\title{
A TECNOLOGIA EDUCATIVA NA PALESTINA: Da Omarieh School à Universidade Islâmica de Gaza
}

\author{
Marcelo Mendonça Teixeira, UFRPE - marcelo.ufrpe.br@gmail.com
}

\begin{abstract}
Resumo. No cenário da Educação contemporânea, as possibilidades de aprendizagem através das interfaces multimídia surgem como uma resposta ao ensino tradicional, linear e padronizado. No decorrer dos anos, as tecnologias educacionais tornaram-se fáceis de usar e permitem que haja muitos emissores, muitos receptores e uma quantidade significativa de intercâmbios e cooperação entre educandos e educadores, gerando redes colaborativas de conhecimento. Foi esse cenário que nos motivou a pesquisar as tecnologias educacionais utilizadas no processo de ensino e aprendizagem no Oriente Médio, particularmente, na Palestina, do ambiente escolar à universidade. A pesquisa foi realizada no primeiro semestre de 2014.
\end{abstract}

Palavras-Chave: Palestina, Israel, Tecnologia Educativa, Interfaces.

\section{THE EDUCATIONAL TECHNOLOGY IN PALESTINE: From Omarieh School To The Universidade Islâmica de Gaza}

\begin{abstract}
In the scenario of contemporary education, learning opportunities through multimedia interfaces arise as a response to traditional, linear and standardized education. Over the years, educational technologies have become easy to use and allow for too many issuers, many receptors and a significant amount of exchanges and cooperation between educators and students, generating collaborative knowledge networks. It was this scenario that motivated us to investigate the educational technologies used in the teaching and learning process in the Middle East, particularly in Palestine, from the school environment to university. The research was realized in the first half of 2014.
\end{abstract}

Keywords: Palestine, Israel, Educational Technology, Interfaces.

\section{INTRODUÇÃO}

Como uma abordagem sistémica que integra várias funções do processo educativo, do ensino básico ao superior, as tecnologias educativas vêm a constituir modos diferenciados de ensinar e aprender, possibilitando a oportunidade de se produzir conhecimento por novas vias. Aqui, nasce uma nova perspectiva para o processo educativo tradicional, hierarquizado e linear, relacionando a comunicação mediada por recursos tecnológicos, a didática, os métodos e as técnicas de ensino, norteado pela isenção da presencialidade corpórea. Reflexo dessa realidade, a tecnologia educativa, está presente e disseminada em instituições de ensino em todo mundo, de ditaduras e democracias, independente da situação socioeconômica vivenciada. 
Partindo dessa premissa, apresentamos, neste trabalho, uma investigação empírico descritiva de cariz qualitativo em instituições de ensino palestinas, abordando as tecnologias educativas utilizadas pela comunidade docente da Omarieh School, em Jerusalém (Cijordânia), e pela comunidade discente da Universidade Islâmica de Gaza, localizada na Faixa de Gaza.

\section{METODOLOGIA}

Como mencionado em epígrafe, a metodologia adotada é de natureza qualitativa e de caráter empírico descritivo, orientando-se pelo Estudo de Caso da Omarieh School, em Jerusalém, e da Universidade Islâmica de Gaza (UIG), em Gaza. Optamos pelo estudo de caso por indagarmos questões do tipo "como" e "porque”, bem como por investigar um fenômeno contemporâneo dentro de seu contexto real, compulsoriamente mencionadas na obra de Robert Yin (2012), expoente dos "Case Studies". O teórico sublinha que cada caso é um caso e deve ser tratado de acordo com suas características e particularidades, às quais podem ser as mais variadas, tanto qualitativas quanto quantitativas. Nesse sentido, o objetivo fulcral da pesquisa de campo foi conhecer e analisar as tecnologias educativas utilizada no processo de ensino- aprendizagem de crianças a universitários em instituições de ensino palestinas, bem como o processo de interação entre docentes, discentes e seus pares no ambiente educacional.

Para tanto, recorremos a cinco perguntas abertas e fechadas em um formulário, numa amostra composta por 26 universitários de diferentes cursos da Universidade Islâmica de Gaza e 4 professores da Omarieh School, no primeiro semestre de 2014. Os dados foram inseridos e tratados na plataforma Qualtrics Survey. As perguntam versaram sobre:

1. Mediante suas funcionalidades, as tecnologias de informação e comunicação podem contribuir para melhorar o processo de ensino e aprendizagem? Se positivo, por qual motivo? Escolha uma das opções:
a) Interação
b) Colaboração
c) Comunicação Síncrona e Assíncrona
d) Flexibilidade de Horários
e) Baixo custo
f) Troca de informações e saberes entre docentes, discentes e seus pares
g) Não trazem nenhuma contribuição

2. Tecnologias educativas são utilizadas no processo de ensino-aprendizagem em sua instituição de ensino? Se positivo, quais são os principais recursos em uso?
a) Facebook
b) E-mail
c) Youtube
d) Podcast
e) Chat
f) Fórum
g) $\mathrm{Blog}$ 

h) Picasa
i) Google Docs
j) Twitter
l) Skype
m) Planilhas Eletrônicas
n) Plataforma de e-learning

\section{As tecnologias educativas ajudam na realização de atividades escolares? Sim ou} Não.

\section{O desenvolvimento tecnológico substituirá o educador no futuro? Sim ou Não, ou Tem Dúvida.}

\section{Os educadores incentivam a utilização de tecnologias educativas como interfaces de apoio didático? Sim ou Não.}

A partir dessas questões, adicionado a uma revisão de literatura, discutimos a pesquisa empírico-descritiva em voga.

\section{A EDUCAÇÃO NA PALESTINA}

No cenário da educação, e mais precisamente, no contexto da educação online, as possibilidades de aprendizagem através das interfaces da Web surgem como uma resposta ao ensino tradicional, carteziano linear e padronizado, além da estrutura estática da Internet. Deste modo, as aplicações tornaram-se fáceis de usar, permitindo que haja muitos emissores, muitos receptores e uma quantidade significativa de intercâmbios e cooperação, gerando redes colaborativas de conhecimento.

Moran, Masetto e Behrens, em 2003, já alertavam que precisávamos reinventar a forma de ensinar e aprender, presencial e virtualmente, diante de tantas mudanças na sociedade e no mundo do trabalho. Os modelos tradicionais são cada vez mais inadequados. Educar com novas tecnologias é um desafio que até agora não foi enfrentado com profundidade. Temos feito apenas adaptações, pequenas mudanças. Agora, na escola e no trabalho, podemos aprender continuamente, de forma flexível, reunidos numa sala ou distantes geograficamente, mas conectados através de redes (ibidem). Tal discurso ecoa na atualidade do cenário brasileiro e de outros países da América Latina, que pouco ou nada mudaram em uma década, com exceção da compra de equipamentos para uma população docente e discente nas instituições de ensino, e que em sua maioria não sabe utilizá-los em simetria com o universo de possibilidades educacionais que a Internet dispõe a seu favor. Enfim, a ascensão da cultura da informação e da participação nos dias atuais ratificou no imaginário acadêmico uma cultura imanente da sociedade em rede, apesar se fazer notório que máquinas e softwares sofisticados não garantem a aprendizagem. Tão verdade quanto, é constatar que a introdução de tecnologias educacionais no ambiente escolar não fazem diferença quando o aspecto "aprendizagem". Na antítese do panorama ocidental, vemos que em alguns países do Oriente Médio, como em Israel e na Palestina, tecnologias educacionais são bem vindas como interfaces de apoio didático, mas o papel do educador é fundamental na formação do educando, ou seja, valorização e respeito são 
palavras de ordem no cotidiano desses países, mesmo que não se traduzam em bons salários ou infraestrutura da instituição de ensino (o que não é o caso de Israel).

\subsection{O Sistema Educacional Palestino}

Democracia Parlamentarista e República Semipresidencialista, o Estado da Palestina é reconhecido como país pela Organização das Nações Unidas e por mais de 130 países, incluindo o Vaticano e o Brasil. Sua capital é Ramallhah e Jerusalém Ocidental (na Cirjordânia). Jerusalém igualmente é declarada, mas não reconhecida pela comunidade internacional, por Israel, como capital. Com apenas 365 quilômetros quadrados, a capital da Faixa de Gaza é Gaza e faz fronteira com o Egito e Israel. Outras importantes cidades são Khan Yunis, Rafah e Dayr Al-Balah. A Educação na Palestina limita-se aos territórios da Cijordânia, parcialmente ocupada militarmente por Israel, mas reclamada pela Autoridade Palestina (controlada pela Fatah - Harakat al-Tahrir al-Watani alFilastini ou Movimento de Libertação Nacional da Palestina) e pela Jordânia, e a Faixa de Gaza (controlada pelo Hamas - Ḩarakat al-Muqāwamat al-Islāmiyyah ou Movimento de Resistência Islâmica). Tanto na Cijordânia quanto em Gaza, o sistema educacional é administrado pelo Ministério Palestino de Educação e Ensino Superior.

São três diferentes tipos de escolas seccionadas a partir de gênero em territórios palestinos, de acordo com Mustafa e Bisharat (2008), a escola de meninos, a escola de meninas e a escola co-educacional divididas em graus, no ensino básico, do $1^{\circ}$ ao $10^{\circ}$. O ensino secundário representa o ensino médio ou profissionalizante (em escolas técnicas), abrangendo o $11^{\circ}$ e $12^{\circ}$ graus e, por fim, o ensino superior, com cursos de graduação em diferentes campos do saber, oferecidos em 13 instituições de ensino (públicas e privadas), algumas das quais oferecem cursos de pós-graduação, além de institutos de pesquisa em Jerusalém e em Gaza. Em relação ao currículo, a Educação segue a manuais, padrões e regulamentos próprios, em parte, influenciados pela "UNESCO International Institute For Educational Planning" e pelo sistema árabe de ensino. Também existe as Escolas-Albergue da Agência da ONU para Refugiados Palestinos, na Faixa de Gaza. A estrutura administrativa da Educação é composta de diretorias (escritórios distritos), divididos na Cisjordânia e na Faixa de Gaza. A Al-Quds Open University é especializada em ensino à distância para a comunidade palestina e a Universidade de Al-Aqsa, em Gaza, se destaca por exportar "mentes" para as melhores universidades de tecnologia norte-americanas. O financiamento para a Educação se origina do orçamento do governo através do Ministério das Finanças Palestino conjuntamente com doações de organismos internacionais, como a UNESCO. As escolas da ONU e as faculdades comunitárias recebem verba da União Europeia.

Nos últimos anos, a Universidade Islâmica de Gaza vem se destacando como uma das principais instituições de ensino superior do Oriente Médio, aliás, competindo, em algumas áreas, com instituições consagradas mundialmente, como a Universidade Hebraica de Jerusalém, a Universidade de Haifa e a Universidade de Tel Aviv (em Israel), a Universidade King Saud e a King Abdulaziz (na Arábia Saudita). Recentemente, estabeleceu um acordo de cooperação com a Universidade do Porto, de Portugal, para o intercâmbio de pesquisadores e estudantes, e a realização de eventos acadêmicos entre ambas instituições (seminários, workshops, palestras). De acordo com o Website da UIG - http://www.iugaza.edu.ps/en/About-IUG/News/Details/id/15151 a instituição tem parceria com mais de 143 institutos acadêmicos e organizações em todo o mundo. 
Um dos aspectos em evidência na pesquisa foi, sem dúvida, o grau de conhecimento dos alunos de graduação da UIG sobre diversos assuntos em decorrência no Ocidente, em vantagem de estudantes de mesmo nível acadêmico de alguns países desenvolvidos, onde muitos se limitam a estudar a história local ou no máximo, de seu continente. Na Omarieh School, em Jerusalém, notamos a mesma trajetória entre os docentes e todos com um bom nível de fluência do idioma Inglês. O livro de Nasser, Berlin e Wong (2011) "Examing education, media and dialog under occupation: the case of Palestine and Israel", desmistifica como palestinos, não somente universitários, entendem e se comunicam bem em Inglês, num cenário de educação precária. Os Acordos de Oslo, em 1993, propiciaram o surgimento da Autoridade Nacional Palestina, compreendendo as Regiões da Cijordânia e da Faixa de Gaza, e frente a um panorama de reconhecimento internacional como "Estado" no futuro, era necessário investir na segunda língua, além do Árabe. Daí, houve uma mudança no currículo e todas as insitutições de ensino introduziram tal idioma na grade curricular do ensino básico ao superior. Inclusive, por receberem alunos estrangeiros de intercâmbio e professores pesquisadores de várias nacionalidades, é muito comum o diálogo em Inglês nos campus acadêmicos, como podemos verificar na Universidade de Birzeit (Cijordânia), e na Universidade Islâmica de Gaza. Em contrapartida, também nos foi revelado que as retrições de acesso ao mercado de trabalho em Israel e a escassez deste nos territórios palestinos influenciam negativamente na perspectiva dos jovens em fazer um curso superior, tanto na Faixa de Gaza quanto na Cijordânia. Ainda, as limitações orçamentárias para a aquisição de materiais didáticos, computadores e softwares, entre outros problemas inerentes a um cenário de conflito entre dois países há décadas, reduzem, consequentemente, as possibilidades de crescimento e a oferta de ensino na Palestina. Por conta dos conflitos com Israel, existe preconceito no universo acadêmico Ocidental sobre o desenvolvimento tecnológico na Palestina e o "achismo", sem conhecimento de causa, prejudica, efetivamente, a imagem do país em busca de reconhecimento científico da comunidade internacional. A realidade é inversa quando presenciamos os fatos "in loco".

Em 2013, a pertinente reportagem do Jornalista Guilherme Pavarin da Revista Galileu "Conexão Palestina" ${ }^{1}$ reforça nossos argumentos. Oportuno para o artigo, citamos partes do texto de Pavarin: "Nos últimos meses, a atuação dos militantes digitais da Palestina tem se voltado a trazer as universidades para próximo do setor da tecnologia"..."Entre as start-ups que concorrem aos investimentos estão ideias promissoras. Uma delas, chamada imbox, é um aplicativo que cria listas inteligentes de músicas com base em grupos de amigos. O autor, Mohammad Khatib, um engenheiro de software de 24 anos, cabelos compridos e de passagem pelo Google, explica que o programa pode detalhar com precisão se os usuários gostarão de uma música escaneando tudo o que falam e dizem pela internet. "Estamos usando essa plataforma para entender como as interações das pessoas influenciam as outras", diz. "Depois poderemos aplicar às áreas de notícias, artigos, e assim por diante”. Na pesquisa com os quatro professores da Omarieh School e com alunos de diferentes cursos da Universidade Islâmica de Gaza tivemos uma percepção subliminar, face ao quantitativo da amostra inquirida, sobre as tecnologias educativas no processo educativo e o que tais recursos representam para a comunidade escolar e universitária palestina. Observemos:

${ }^{1}$ Fonte: Disponível em: http://revistagalileu.globo.com/RevistaCommo/0,EMI296260-17773,00-CONEXAO+PALESTINA.html. Acesso em 3 de Agosto de 2014. 
Gráfico 1. Tecnologias educativas são utilizadas no processo de ensinoaprendizagem em sua instituição de ensino? Se positivo, quais são os principais recursos em uso?

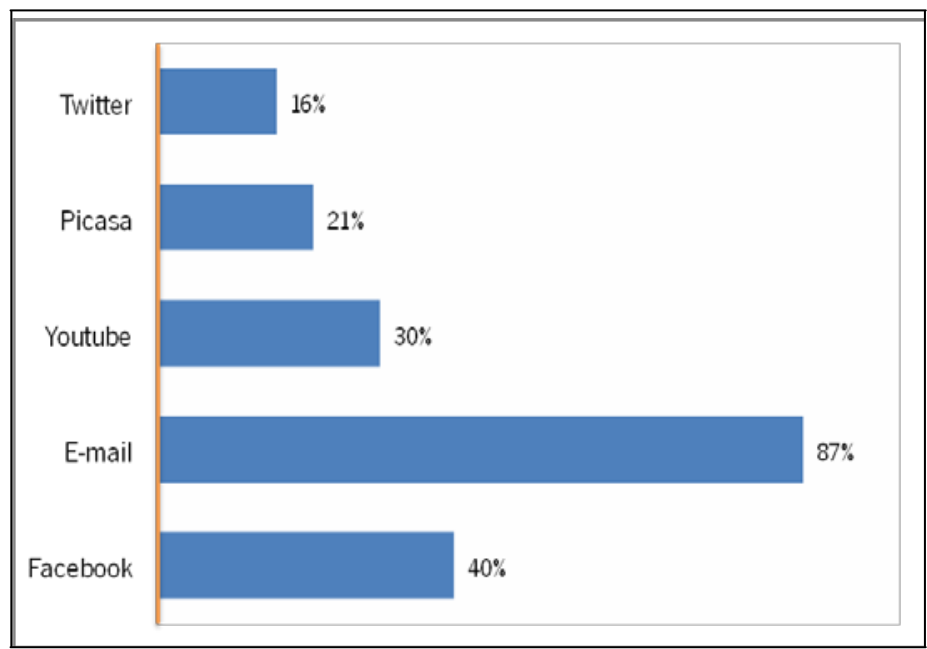

Os maiores percentuais corroboram com o pensamento de Macluhan (1972) na "Galáxia de Gutemberg: a formação do homem tipográfico", quando diz que as tecnologias de informação e comunicação reduzem a distância entre as pesssoas, e tal processo tecnológico tende a reduzir o planeta à mesma situação de uma Aldeia, em que todos os habilitantes estariam conectados, alusão a "Aldeia Global". É fato que as TICs promovem, efetivamente, uma comunicação síncrona e assíncrona e fortalecem a interação entre os pólos da comunicação, com flexibilidade de horários e em processo colaborativo para a troca mensagens, com menores custos no universo virtual em relação a outras formas de comunicação mediada, como o telefone. Teixeira e Ferreira (2014) afirmam se tratar de uma virtualização cultural da humanidade, fruto da migração do espaço físico para o virtual, regido por códigos, signos e relações sociais próprias. Avante, surgem formas instantâneas de comunicação, interação e possibilidade de rápido acesso às informações, no qual não somos meros emissores, mas produtores, reprodutores, colaboradores e distribuidores daquelas.

As novas tecnologias também têm servido para "conectar" pessoas de diferentes culturas fora do espaço virtual, o que há pelo menos cinquenta anos era impensável. Nessa gigantesca teia de relacionamentos, absorvemos, reciprocamente, crenças, costumes, valores, leis, hábitos, uns dos outros, heranças culturais eternizadas por uma dinâmica físico virtual em permanente metamorfose. Daí se estabelece uma permuta da sociedade da informação para a sociedade do conhecimento, e desta para a sociedade em rede, conectada e destituída de presencialidade corpórea. Com base nos dados apresentados fica patente que as necessidades comunicacionais convergem entre os seres humanos, independente de credo, cor ou raça, regidos pelo troca de informações.

O perfil de utilização de educadores da Omarieh School concentra-se na utilização do E-mail e do Facebook para a interação com seus pares (seus alunos são de classes iniciais do ensino básico), enquanto os estudantes da UIG têm perfis de utilização mais amplos em relação a utilização de tecnologias educacionais como interfaces de apoio didático, e em nada diferem-se de qualquer instituição de ensino do Ocidente. Os fatos comprovam a veracidade da afirmativa. No mês de Julho de 2014, o 
Bacharel em Sistemas de Informação Alexandre Bezerra realizou uma pesquisa de campo na Faculdade Escritor Osman da Costa Lins, em Pernambuco - Brasil, com foco na identificação dos recursos tecnológicos mais utilizados por alunos e professores daquela instituição e os resultados assemelham-se aos da universidade palestina em questão. Em simetria com a vertente educativa, tais interfaces transformam-se num canal de mobilização social em prol de valores e ideias no meio acadêmico, rediscutindo às informações veiculadas pelos meios de comunicação e dando a esta uma roupagem questionadora, crítica, ativa. A cibercultura floresce nesse cenário, influenciada em sua gênese pelos movimentos de comunicação em rede. Por outro lado, as sociedades têm passado por grandes mudanças ao longo dos anos causadas pela influência dos avanços tecnológicos em todas as esferas sociais e áreas do saber. Vive-se a era do online, onde as novas compreensões de tempo/espaço conferem um novo status à educação, por meio essencialmente do fenômeno da socialização do conhecimento que ocorre em escala global, num ambiente de partilha de experiências, informações, vivências e aprendizado em rede. Por sua vez, a "sociedade de informação e do conhecimento" configura-se como um estágio natural e evolutivo no desenvolvimento social das pessoas, proveito de um mundo cada vez mais interligado pelos novos meios de comunicação.

Constatamos que a troca de informações em texto, vídeo, áudio e/ou imagem assíncronas através do e-mail, ao mesmo tempo, a construção coletiva de conhecimentos no Google Docs e a utilização das planilhas eletrônicas para finalidades que vão da organização de dados de uma pesquisa a resolução de problemas matemáticos, aliados a ambientes virtuais de aprendizagem, como as interfaces de preferência dos acadêmicos inquiridos. Quando questionados se as tecnologias educativas ajudam na realização de atividades escolares (pergunta 3), a regência das opiniões tocaram a nota unissonamente, numa orquestra em concordância na negativa de que os desenvolvimento tecnológico não irá substituir o educador no futuro (pergunta 4), e confirmando que os maestros do ensino básico ao superior utilizam tecnologias educativas como interfaces de apoio didático no processo educativo, seja de forma presencial ou à distância (pergunta 5). Doravante, são discursos inerentes as potencialidades e os contributos da informática na educação e que podem ser disseminadas em todos campos do saber. Horizontes que transitam das engenharias à educação. Entre Julho e Agosto de 2014, após os ataques da "Operação Margem de Proteção" por parte do Governo de Israel na Faixa de Gaza, constatamos que a UIG foi parcialmente destruída e serão necessários bilhões de dólares para restaurar o que antes era uma esperança de vida próspera a partir do ensino superior para aproximadamente 20.000 alunos.

Desde 1990 que os livros e artigos de Riad Malki denunciam que os israelenses impõem normas restritas ao desenvolvimento científico e tecnológico das universidades palestinas, entre as quais se prolongam até 2014, como: a não expansão do ensino universitário e construção de novas instalações (departamentos e centros de ensino), dificuldades para a entrada de equipamentos de laboratórios na Faixa de Gaza, computadores e livros para as bibliotecas apreendidos, etc. Nesta seara de absurdos, autorizações de viagem negadas a professores universitários para a participação de eventos acadêmicos no exterior. Ainda, uma ordem militar que impede a circulação, venda e manutenção como bens de uso pessoal, de nada menos que 6 mil títulos de obras, livros didáticos e publicações científicas, conta o estudioso Riad (ibidem). Os fatos exprimem um receio infundado no crescimento científico das universidades palestinas como elevadores panorâmicos para o discurso ultranacionalista dos grupos 
Hamas e Jihad Islâmica e/ou o desenvolvimento/aprimoramento de armas e técnicas de guerrilha contra a população judia. É claro que há lógica no medo por trás dessa ideologia repressora, afinal, o "Bloco de Estudantes Islâmicos" é um movimento precursor do Hamas e nasceu na Universidade Islâmica de Gaza. Outro motivo é que centenas de morteiros e foguetes Qassam (de fabricação caseira e aperfeiçoados nos laboratórios da IUG, de acordo com o Governo de Israel) são enviados a partir da Faixa de Gaza contra o território judeu, atigindo, frequentemente, a cidade de Sderot e Ashkelon, justificando, assim, o sionismo extremista e o direito de resposta ao antissemitismo. Lembrando que a relação de Benjamin Netanyahu (Primeiro Ministro de Israel) com a Fatah de Mahmoud Abbas (Primeiro Ministro Palestino na Cijordânia) não é menos tumultuada. A questão é complexa, se levarmos em conta que Israel ocupa áreas da Palestina desde a guerra dos seis dias, em 1967, e os assentamentos não páram de ser construídos em terras que não lhes pertence, além dos checkpoints (postos de controle) e do muro de quase $800 \mathrm{~km}$ de extensão (com 3 metros de largura e 8 metros de altura, iniciado em 2002), que separa a população da Palestina (em territórios ocupados da Cijordânia) de Israel, supostamente, visando eliminar os constantes atentados terroristas e os conflitos com os Árabes. Em 2004, o muro foi declarado ilegal pelo Tribunal Internacional de Justiça de Haia, mas Israel ignora a lei e continua a expandir sua construção. Jerusalém é, sem dúvida, uma das cidades mais impressionantes em relação a "tolerância" do mundo, ao agregar os bairros armênio, cristão, judeu e mulçumano, cada qual com seus ritos e atribuições específicas em locais sagrados. Idem, foi a tolerância nas escolas e universidades para realização da presente pesquisa, mas limitada, em algumas ocasiões, pela segurança escolar, que não permitia fotografias ou filmagens sem prévia autorização.

Enquanto o povo palestino é prejudicado pelos grupos radicais islâmicos, sem possibilidade de diálogo coerente, pois as exigências que demandam nenhuma nação conseguiria atender, Israel têm ilhas acadêmicas de excelência, como a Universidade Hebraica de Jerusalém, o Instituto de Tecnologia de Israel e o Instituto Weizmann de Ciência, entre as 100 melhores universidades do mundo em 20132, segundo a "Academic Ranking of World Universities", de onde nascem prêmios nobel e reconhecimento internacional. Em visita a Universidade de Tel Aviv, por exemplo, em Julho de 2014, foi-nos facultado um mapa virtual do campus universitário para chegar a Escola de Educação, quanto normalmente seria deslocado um funcionário para guia-nos até o local de encontro. Naquela ocasião, a infraestrutura das instalações impressionou pela sofisticada tecnologia empregada nos laboratórios e nas confortáveis salas de aula da instituição. Porém, o presente estudo não julga ou emite pareceres a respeito da causa palestina ou judia. Em Tel Aviv, Jerusalém, Gaza, Ramallah, perguntamos a crianças e jovens judeus e palestinos de diferentes idades porque existe guerra, e eles responderam unicamente "porque querem tomar nosso território, nossa terra". A certeza repercute na incerteza de um futuro próspero para aquela região, especialmente na Faixa de Gaza e na Cijordânia, congénere a um Estado-Providência.

\section{CONCLUSÃO}

Em linhas gerais, confirmamos a utilização de tecnologias educacionais no processo de ensino e aprendizagem da Palestina, tanto como recursos complementares às aulas

${ }^{2}$ Fonte: disponível em: www.shanghairanking.com/ARWU2013.html. Acesso em 7 de Agosto de 2014. 
lecionadas, quanto como interfaces de comunicação síncrona e assíncrona, demonstrando, ao longo de toda a pesquisa, que $100 \%$ da comunidade escolar e universitária inquirida fazem parte da "Geração Millennials" ou "Geração Y", espelho de uma cultura virtual ou de uma cibercultura. Trata-se de um panorama positivamente divergente de muitos países do Continente Africano (Libéria, Niger, Zimbabuwe) ou do Oriente Médio (Síria, Iraque, Iémen). Com a interatividade multimídia emerge um novo modelo de comunicação, com cidadãos ativos e intervenientes que interagem diretamente com a fonte da informação e que são eles próprios fontes de informação, esboço do que vimos na Cijordânia e na Faixa de Gaza, antes da recente guerra. Deste modo, atestamos que tecnologias educacionais favorecem a mudança da postura de aprendentes, no sentido de uma maior participação colaborativa no quotidiano escolar, bem como na organização de um novo laço social, agora reunido em torno de centros de interesses comuns, com sua configuração singular, delineado pela própria coletividade escolar.

Outro aspecto observado na pesquisa foi a ampla utilização dos telefones celulares por estudantes da Universidade Islâmica de Gaza e da Omarieh School, e o MLearning deve se fortalecer, tomando proveito deste cenário. Os estudos que abordam comunicação e mobilidade estão atualmente tomando como base os avanços da telefonia móvel com as suas possibilidades interativas. A comunicação móvel ganha espaço em todos os setores da sociedade por conseguir integrar uma grande variedade de interfaces multimídia num mesmo equipamento (câmera fotográfica, rádio, gravador de áudio e vídeo, televisão, editor de texto, acesso a Internet,...), aliado a praticidade, flexibilidade, dinamismo e, principalmente, mobilidade, mas ainda pouco aproveitado como interface educacional na Palestina. Números e percentuais não representam a grandiosidade da vontade humana em aprender e transmitir conhecimentos. Se por um lado, vemos uma utilização subliminar das interfaces multimídia na educação palestina, por inúmeros motivos, na contra mão, um povo que se esforça para crescer e desenvolver-se em diferentes campos do saber diante dos embargos e limitações inglórias impostas pelo Governo de Israel. Como já comentado, em outras palavras, tecnologias educativas permitem uma constante interação emissor/receptor que anula a sequencialidade, linearidade e horizontalidade própria do ensino tradicional, concentrando em si diferentes formas de contato temporal com a mensagem informativa audiovisual e hipertextual. Do surgimento de novos gêneros as formas de interagir com o público estudantil, surge na Internet uma nova linguagem comunicativa, favorecida pela incorporação de novos elementos à sua estrutura discursiva e pela maneira como o cibernauta toma uma atitude ativa de pesquisa e consumo dos conteúdos, comprovados na pesquisa em voga. As próprias características do nível de formação acadêmica justificam a preferência discente por interfaces buscam conteúdos que elevam o nível de conhecimento sobre determinado assunto ou acrescentem informações ao objeto de estudo em investigação na UIG. Enquanto os docentes da Omarieh School priorizam o uso de tais interfaces para a comunicação síncrona e assíncrona. A influência dos avanços tecnológicos influenciam diretamente nas transformações sociais num mundo em que pensamos globalmente e agimos localmente. É nesta perspectiva que se clarifica o quão necessário é investigar a influência das tecnologias de informação e comunicação nos contextos culturais e educacionais, de onde se originam e como operam, incluindo sua inclinação para os valores sociais dominantes de racionalidade, trabalho, linguagem, comunicabilidade, aos dogmas religiosos. Em suma, palestinos e israelenses fazem parte de uma tribo digital na Aldeia Global. 


\section{REFERÊNCIAS}

MALKI, R.. A questão da tecnologia no processo de paz. In: Dupas, G. \& Vigevani, T. (Org). A construção da paz vista de uma perspectiva global. São Paulo: Editora Unesp, 2002, p. 81-132.

MACLUHAN, M.. Galáxia de Gutemberg: a formação do homem tipográfico. São Paulo: Edusp, 1972.

MUSTAFA, M. M.; BISHARAT, K.. Palestinian National Authority. In: Ina Mullis, M. et al. Encyclopedia: a guide to mathematics and science education around the world. Boston: TIMSS \& PIRLS International Study Center, 2008.

NASSER, I.; BERLIN, L.; WONG, S.. Examing education, media and dialog under occupation: the case of Palestine and Israel. Bristol: British Library, 2011.

TEIXEIRA, M. M; FERREIRA, T. A. E.. Tecnologias de informação e comunicação: protagonistas da comunicação virtual. Munique: Grin Verlag, 2014.

YIN, R.. Applications of case study research. London: Sage, 2012. 